Article

\title{
Exploring the Intersection between Engineering and Sustainability Education
}

\author{
Denise Wilson $\mathbb{D}$
}

Department of Electrical and Computer Engineering, University of Washington, Seattle, WA 98195-2500, USA; denisew@uw.edu; Tel.: +1-206-221-5238

Received: 1 May 2019; Accepted: 28 May 2019; Published: 3 June 2019

Abstract: Sustainability and sustainable development are cornerstones of many of the greatest challenges that engineering faces in the 21st century. Yet, most engineering programs do not explicitly prepare students to engineer within the bounds of sustainability. While engineering education must change in order to more fully integrate sustainability, such change should leverage intersections among what engineering students bring to the table, how engineering educators teach, and the sustainability challenges defined by experts in engineering. This study focuses specifically on what students are bringing to the table by first comparing what students intend to contribute to a more sustainable world to what they should contribute as defined by the grand challenges of engineering. Qualitative analyses of what students say about how they intend to contribute to sustainability show that these statements cover only a small subset of the grand challenges. Additional quantitative analyses show that more engineering students than students in non-STEM fields (business and education) have a strong sense of personal responsibility regarding critical sustainability issues in sustainable energy and waste management. These results suggest that, with proper intervention from engineering educators, engineering students are well positioned and motivated to pursue and expand their sense of responsibility for sustainability.

Keywords: engineering; education; sustainability; social responsibility

\section{Introduction}

The United Nations made sustainable development a global priority with Agenda 21 during the 1992 Earth Summit and most recently with Agenda 2030 and its sustainable development goals [1]. The National Academy of Engineering (NAE) has also prioritized sustainability for engineers in the United States [2]. Together, these goals reflect a global concern and commitment to sustainable development and call for engineers to take responsibility for sustainable solutions to complex problems. Building the knowledge base and sense of responsibility for sustainable development among engineers is a process that must begin early in the engineer's career, during the undergraduate years. Yet, integrating sustainability themes into undergraduate engineering education is difficult.

Engineering sits at the intersection between the needs of society and scientific knowledge [3]. This makes engineers critical in both facilitating and leading sustainable development in the 21st century. In turn, engineering educators are tasked with advancing a major shift in mindset from controlling nature to participating with nature and doing so in such a way that synergistically improves both human life and environment [3]. In support of this paradigm shift, the NAE, with input from technology experts around the world, defined 14 grand challenges of engineering based on four cross-cutting themes which include sustainability [2]. Several of these grand challenges focus on a traditional single-pillar, environmentally focused view of sustainability (e.g., develop carbon sequestration methods, manage the nitrogen cycle). However, many challenges also incorporate social and economic pillars of sustainability (e.g., provide access to clean water, restore and improve 
urban infrastructure) associated with the more comprehensive triple bottom line (TBL) approach. Still, other challenges focus on the cross-cutting influence of education (e.g., advance personalized learning) in supporting a more sustainable future alongside environmental, social, and economic dimensions.

When the 14 grand engineering challenges and the 17 sustainable development goals (SDGs) that guide Agenda 2030 are mapped to one another (Figure 1), the intersection between the NAE's priorities and Agenda 2030 is evident. These 17 SDGs as well as Agenda 2030 evolved from the TBL and associated action plan defined by Agenda 21, which, in turn, emerged from the 1992 Earth Summit and was adopted by 178 countries at that time [4]. Agenda 21 set in motion a commitment at local, national, and global levels to sustainable development. Since that time, the language of sustainable development has changed, but the core commitment and goals central to Agenda 21 remain firm. Agenda 21 focuses on four major facets of sustainable development: social and economic aspects, conservation of resources, strengthening the role of major groups, and means of implementation. Many of the Agenda 2030 SDGs are focused on the environment (e.g., \#13 climate action, \#14 life below water, \#15 life on land) while others focus on the economic (e.g., \#8 decent work and economic growth, \#1 no poverty) and social (e.g., \#5 gender equality, \#16 peace, justice, and strong institutions) pillars of sustainability. Furthermore, Agenda 2030 goes beyond the three basic pillars of sustainability by specifically emphasizing education (\#4 quality education) as well as the partnerships (goal \#17) necessary to realistically achieve the SDGs [1].

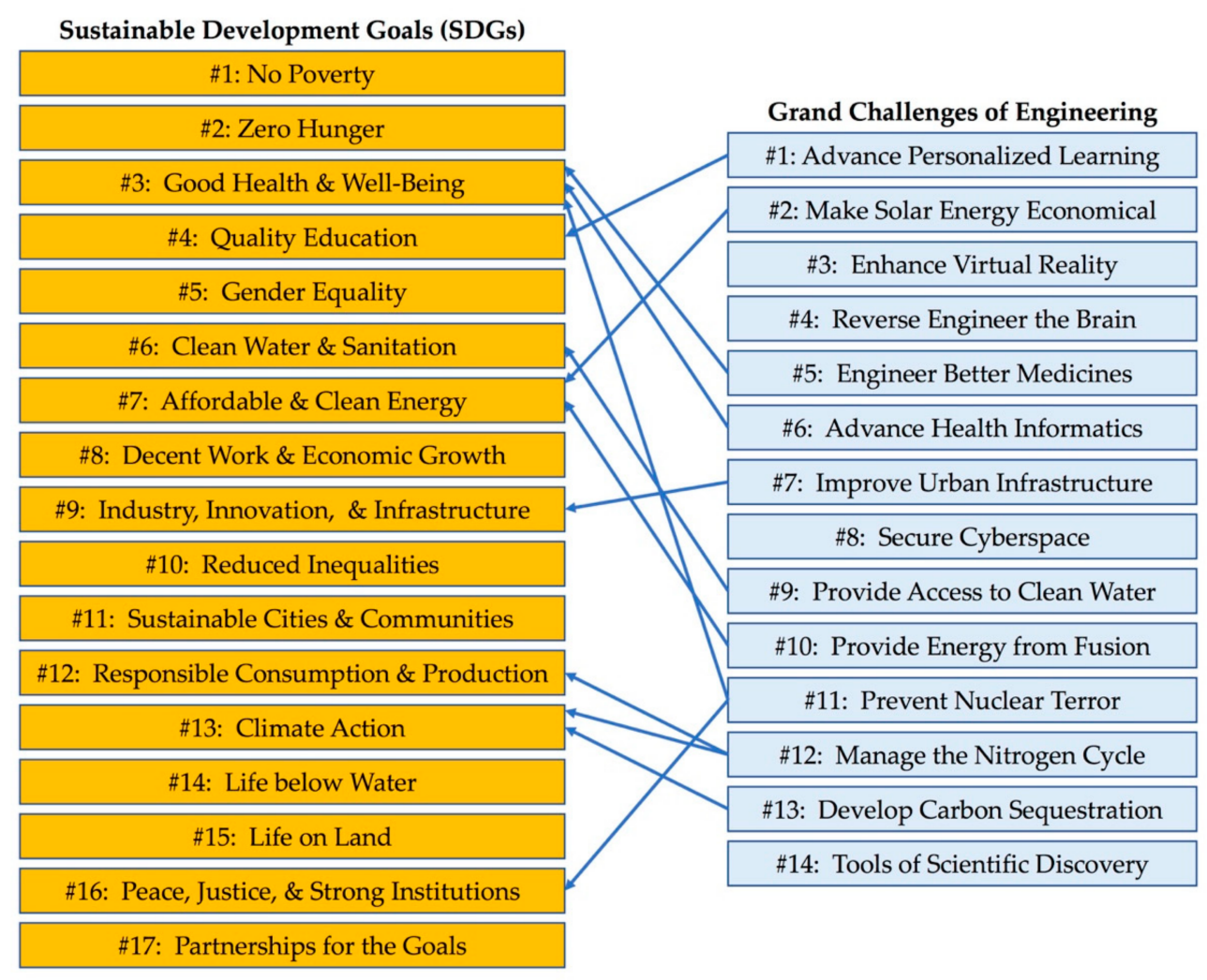

Figure 1. Intersection between sustainable development goals (SDGs) of Agenda 2030 and the National Academy of Engineering (NAE's) grand challenges.

The efforts of the United Nations in adopting far-reaching sustainability goals for the 21st century have provided impetus for educators to incorporate sustainability and sustainable development into K-16 curricula. Likewise, the efforts of the National Academy of Engineering in formulating grand challenges for engineers have stimulated an urgent need for engineering programs in higher education to figure out how, when, and to what extent sustainability should be integrated into existing curricula. The United Nations Agenda 2030 recognized this urgent need for changes in education within all 
disciplines and across all levels of education and expressed it in Target 4.7 under the Quality Education SDG \#4 [5]:

“By 2030, ensure that all learners acquire the knowledge and skills needed to promote sustainable development, including, among others, through education for sustainable development and sustainable lifestyles, human rights, gender equality, promotion of a culture of peace and non-violence, global citizenship and appreciation of cultural diversity and of culture's contribution to sustainable development."

Like the UN Initiative, education for sustainable development (ESD), this target is generalized and has been left ambiguous on purpose so that specific disciplines can implement it within the context of the knowledge and skills inherent to those disciplines. However, such ambiguity has reduced support for the ESD and resulted in poor understanding of how to achieve the plentiful supply of learning outcomes that have emerged from the ESD initiative [6]. On the positive side, many university and college campuses in the U.S. have successfully adopted greening initiatives and pursued research in sustainable development. But, pedagogical strategies to integrate sustainability into the curriculum at a deep enough level to achieve the objectives of the ESD have lagged far behind research and greening [7]. Similar ambiguity has emerged from the broad, multi-faceted call for considering sustainability made by engineering's accreditation board (ABET):

Student Outcome 2: "an ability to apply engineering design to produce solutions that meet specified needs with consideration of public health, safety, and welfare, as well as global, cultural, social, environmental, and economic factors." [8]

In addition to having to resolve how to implement these educational outcomes, engineering faces additional challenges for integrating sustainability into the curricula because engineering teaching remains dominated by lecture-based, content-heavy instruction [9] that is incompatible with effective instruction for sustainable development. Teaching sustainability requires a shift in how engineering educators teach. They must not only develop knowledge and skills but also enable students to shift their values to favor sustainable development [6]. Negotiating shifts in values via indoctrination in a lecture-based environment is prone to failure [10] and instead requires more student-centered learning strategies, including problem-based learning, experiential learning, participatory learning, and applied learning [6]. The end result is that career engineers still produce products that are predominantly unsustainable and engineering students' understanding of sustainability is largely unsatisfactory [11]. Attempts to integrate sustainability into existing curricula have had limited effectiveness and are hampered by students' views that sustainable design is a secondary rather than critical piece of product design [12], by definitions of sustainability that remain narrow and restricted to environmental impacts [13], and by entrenched beliefs that sustainability is outside the scope of an engineering education $[14,15]$.

This study seeks to gain greater insight into the best intersection between where engineering education is now and where it needs to be regarding sustainability education. It does so by first contextualizing what engineering students think is important in terms of what is important to engineering as a discipline. While engineering educators advocate for a heterogeneous and often inconsistent scope of skills and methodologies regarding what engineering students should or should not learn about sustainability [16], few would argue that engineers need not be prepared to contribute to what is important to engineering. Thus, placing what engineering students say they are ready to contribute in their careers into the context of the grand challenges of engineering may be a more effective way to bring more engineering educators onto the same page with regard to sustainability education. Doing so can also expose gaps in engineering education that are relevant not only to sustainable development but to other key societal problems that ultimately attract broader support for curriculum change. In addition to looking at potential gaps between engineering education and the engineering profession in sustainability terms, this study also evaluates differences among engineering and other STEM (environmental sciences) majors and non-STEM majors (business, education). If traditional engineering teaching is not necessarily well positioned to teach all aspects of sustainable development, 
our goal is to identify the best starting points that will nevertheless allow educators to move toward a more sustainability-focused education and a transformation in what engineers seek to do when they graduate.

\section{Materials and Methods}

The goal of this research is to support the development of tools for effectively teaching sustainability in engineering. This study specifically focuses on developing insight into where engineering education best fits in sustainability education. Our first research question (RQ1) is explored via qualitative analysis of a single open-ended survey question where students can freely articulate their intended contributions to sustainability over the course of their careers. The second and third research questions (RQ2 and RQ3) are explored using quantitative analyses of survey data.

\subsection{Research Questions}

\subsubsection{Research Question 1 (RQ1)}

Do engineering students expect to contribute to sustainability in ways that are consistent with national priorities for engineering? As a nation, if the United States expects to meet its grand challenges for engineering in the 21st century, the expectations of engineering students must be aligned with expectations of the discipline. This research question takes a look at how aligned these expectations are by comparing open-ended responses of engineering students to the priorities established by engineering experts in the National Academy of Engineering [2].

\subsubsection{Research Question 2 (RQ2)}

Do students in various (STEM and non-STEM) majors express a different sense of personal responsibility for specific challenges in sustainability? This question offers some insight into the role that engineering (and STEM education) can play in sustainability education. If more engineering students bear personal responsibility for certain challenges of sustainability than students in other fields, these differences suggest logical points of departure for exploring sustainability more broadly in the engineering curriculum.

\subsubsection{Research Question 3 (RQ3)}

How are students' personal knowledge and professional responsibility linked to their sense of personal responsibility for promoting sustainability? Since much of engineering remains lecture-based and focused on the transmission of content, the answer to this question provides insight into how effectively overlaying sustainability content into traditional lecture-based pedagogy can improve individual or personal knowledge and in so doing, enhance the personal responsibility for sustainable development that engineering students take with them into the workforce.

\subsection{Participants}

The population associated with this study consists of 399 undergraduate students (Table 1) in majors associated with business $(21 \%)$, education (10\%), engineering and computer science $(59 \%)$, or environmental sciences (10\%). Approximately $41 \%$ of the sample was female, and the self-reported ethnicities were primarily White $(44 \%)$ and Asian (43\%). Within engineering, the majors most represented in this population were electrical engineering $(58.9 \%)$ and mechanical engineering $(31.6 \%)$, which together make up 48\% [17] of the total engineering bachelor's degrees granted in the United States. In all fields, a majority of participants were upper level (junior or senior): $90 \%$ in engineering, $63 \%$ in education, $85 \%$ in environmental studies, and $79 \%$ in business. 
Table 1. Characteristics of the study population.

\begin{tabular}{cccc}
\hline & Women & Men & Total \\
\hline Total & 164 & 235 & 399 \\
\hline Type of Major & & & \\
Business & 54 & 32 & 86 \\
Education & 35 & 5 & 40 \\
Engineering and Computer Science & 45 & 190 & 235 \\
Environmental Studies & 30 & 8 & 38 \\
\hline Race & & & \\
Asian & 73 & 99 & 172 \\
Black/African American & 2 & 5 & 7 \\
Latino & 10 & 0 & 10 \\
White & 70 & 105 & 175 \\
Other & 6 & 9 & 15 \\
\hline U.S. Citizenship & & & \\
International & 142 & 189 & 331 \\
Age (Mean) & 21 & 44 & 65 \\
\hline GPA (Mean) & 21.8 & 22.1 & 22.0 \\
\hline Citizen or Permanent Resident & 3.45 & 3.52 & 3.50 \\
\hline
\end{tabular}

Background data regarding participant involvement in curricular and extracurricular activities relating to sustainability was not collected in this study. However, Table 2 summarizes relevant courses that students were exposed to within their major, designated by the institution as either related to or focused on sustainability. Sustainability-related courses cover one or more topics that are relevant to at least one dimension of sustainability while sustainability-focused courses are those that focus on all three dimensions of sustainability. The course information in Table 2 provides insight into the extent to which coursework may have influenced student perceptions and responses in this study. Most courses in this list are sustainability focused but emphasize the environmental pillar of sustainability over economic and social aspects. In terms of the amount of coverage in each major associated with this study, environmental sciences had the greatest number of sustainability coursework options (by a wide margin) while business as well as electrical and computer engineering students had the fewest such options within the major.

Table 2. Undergraduate sustainability courses by major.

\begin{tabular}{lccc}
\hline & Sustainability Related & Sustainability Focused & Total \\
\hline Business & 1 & 1 & 2 \\
\hline Education & 2 & 1 & 3 \\
\hline Engineering & & 1 & 2 \\
Electrical and Computer & 1 & 4 & 6 \\
$\quad$ Mechanical & 2 & 28 & 39 \\
\hline Environmental Sciences & $* *$ & 11 &
\end{tabular}

* Includes accounting, entrepreneurship, finance, information systems, management, marketing, operations, and supply chain management. ${ }^{* *}$ Includes two (optional) study abroad experiences.

\subsection{Procedures}

IRB (internal review board) approval was obtained by the investigating institution to recruit, incentivize, and survey students using convenience sampling. Undergraduate participants were recruited into the study over four academic terms. In engineering, participants were recruited from a senior-level design course (11.4\%), a junior-level design course (13.1\%), a junior-level writing course $(21.1 \%)$, and a sophomore-level electronics course (54.4\%). All of these engineering courses had content that related to sustainability (e.g., reducing component count, selecting less hazardous components) but no courses focused on sustainability as a central theme. Participants were provided incentives consisting of a nominal amount of extra credit for the course in which they were recruited. In other 
majors, participants were randomly recruited by email from department or college listservs and given an Amazon gift card for survey completion. Participation in the study was voluntary, and students were assured their survey responses would remain confidential. All students completed an electronic survey online and outside of class. Surveys were collected with identifying information so that duplicate surveys could be removed before aggregating data for analysis. All results were cross-sectional. In the survey, students reported demographic information and responded to affective items that addressed sense of belonging and self-efficacy, as well as to a range of items that assessed global competence, civic engagement, social responsibility, and sustainability.

\subsection{Instruments}

This study focuses on survey responses regarding a single demographic measure (type of major), scales consisting of multiple items, individual items addressing personal responsibility, and a single short answer question. The short answer question, used to address RQ1, was:

What do you believe your most important contribution to sustainability will be as a professional in your chosen field?

RQ2 and RQ3 relied on three scales: A nine-item scale that measured perceptions of professional responsibility for sustainable development, a five-item scale that measured personal knowledge about sustainability, and another five-item scale focused on personal responsibility. Individual items associated with personal responsibility were also used to support analysis of RQ2. Personal knowledge and personal responsibility scales were drawn from previous studies on social responsibility and sustainability, which demonstrated good validity and reliability on scales using these items [18-20].

A modified scale representative of general beliefs about professional responsibility was developed for this study by using exploratory factor analysis of 28 previously used survey items, which addressed what students thought professionals in their chosen field should do regarding various facets of sustainable development. A principal component analysis (PCA) was first performed on all items using no rotation with eigenvalues set to 1 . Communalities were examined to identify problematic variables, and those variables with a communality less than 0.40 were dropped from the analysis. Once these variables were removed, the principal component analysis was repeated until all communalities were greater than 0.40 . Factors that accounted for at least $5 \%$ of the variance in the data were retained for subsequent factor analyses, leading to a total of four factors. Subsequent factor analyses used a Promax rotation because some of the items in the scale were assumed to be correlated. The first of the four factors (which explained $25 \%$ of the variance in the data) was retained to represent students' sense of professional responsibility. The personal knowledge scale was extracted from five items, which evaluated student perceptions on five specific issues in sustainability. All five issues (climate change, sustainable energy, resource scarcity, waste electronics, and access to education) were compatible with the TBL (triple bottom line) approach to sustainability, which balances considerations of social, economic, and environmental impact in sustainable development. The personal knowledge scale represented $60 \%$ of the variance in the data consisting of these five items. Finally, personal responsibility was evaluated based on the same specific challenges in sustainability as were assessed regarding personal knowledge. Five items, each focusing on a different challenge, were aggregated into a single factor that represented $64 \%$ of the variance in the data. Sample items for this and the other two scales used in this study are provided in Table 3. In addition, each single item in personal responsibility was also retained to perform frequency analyses to understand differences among majors associated with RQ2. 
Table 3. Survey items and scales.

\begin{tabular}{ll}
\hline \multicolumn{1}{c}{ Scale } & Sample Items \\
\hline $\begin{array}{l}\text { Professional Responsibility } \\
(\alpha=0.905)\end{array}$ & $\begin{array}{l}\text { Professionals in my intended career should conserve and improve natural } \\
\text { ecosystems while protecting human health and well-being. } \\
\text { Professionals in my intended career should minimize depletion of natural } \\
\text { resources. }\end{array}$ \\
\hline $\begin{array}{ll}\text { Personal Knowledge } \\
(\alpha=0.849)\end{array}$ & $\begin{array}{l}\text { I know a great deal about resource scarcity in the world today. } \\
\text { I know a great deal about access to education around the world today. }\end{array}$ \\
\hline $\begin{array}{l}\text { Personal Responsibility * } \\
(\alpha=0.869)\end{array}$ & $\begin{array}{l}\text { I feel responsible for addressing global resource scarcity in my work/career. } \\
\text { I feel responsible for improving the sustainability of energy in my work/career. }\end{array}$ \\
\hline \multicolumn{2}{c}{ Individual items from this scale were also retained for frequency analyses related to RQ2. }
\end{tabular}

\subsection{Data Analysis}

Short answer data regarding students' intended contributions to sustainability were analyzed using qualitative methods involving a multi-step phase analysis consistent with that described in [21-23]. Short answer data were cleaned, de-identified, and aggregated into a single MS Excel spreadsheet before analysis. Responses were then coded according to the 17 SDGs outlined by Agenda 2030 [1], which build on the millennium development goals by emphasizing human rights and gender equality alongside goals that balance the social, economic, and environmental dimensions of sustainability. Codes were assigned based on a primary goal that was most substantively represented in a student's response. A second pass at the data then included any additional SDGs that were consistent with the student's response. Student responses that were too generalized to align with a specific SDG(s) were coded separately (code $=-1$ ) as were student responses that did not pertain to TBL concepts of sustainability at all (code $=0$ ).

Multiple strategies were used to maintain the quality of data collection and handling by preserving validity and improving reliability of the data consistent with the quality framework provided by Walther, Sochaka, and Kellam [24]. To preserve validity of the analysis results, short answer data were coded according to globally accepted contexts for sustainability embodied by the 17 SDGs of Agenda 2030. Care was also taken during data collection and handling to ensure reliability of the results. Unlike focus groups and interviews, where what researchers say and how they ask questions may expose researcher bias and thus influence student responses, the short answer question in our survey was answered remotely and was less vulnerable to such bias.

Data from Likert-scale items and scales used to explore RQ2 and RQ3 were analyzed using SPSS 19 to compute descriptive statistics, test the reliability of the scales, conduct frequency analyses and analyses of variance (ANOVA) by type of major, and construct the linear regression models for analysis. In RQ2, frequency statistics were tabulated by type of major (business, education, engineering, and environmental sciences) for five personal responsibility items and subsequent analyses using chi-squared tests of independence used to understand differences by type of major. The strength of differences was evaluated using effect sizes based on Cramer's V [25]. In RQ3, descriptive statistics and ANOVAs were first used to identify any significant differences in the independent variables. Then, a hierarchical linear regression model was used to understand how type of major, professional responsibility, and personal knowledge predicted personal responsibility. For the regression models, field of study was effect coded as summarized in Table 4 with engineering as the baseline field (coded as -1 for all effect coded variables). Type of major was coded in the lowest level of the model using these effect codes and professional responsibility and personal knowledge were inserted in the second level of the model. Any interactions that emerged as potentially significant were then evaluated in the third and last level of the regression model. The strength of the regression models was evaluated using the $\mathrm{r}^{2}$ coefficient of determination. 
Table 4. Effect coding of independent variables for linear regression models.

\begin{tabular}{ccl}
\hline & Variable Name & \multicolumn{1}{c}{ Effect Coding } \\
\hline \multirow{3}{*}{ Type of Major } & Business & Business $=1$; Education $=0$; Environment $=0$; Engineering $=-1$ \\
\cline { 2 - 3 } & Education & Business $=0$; Education $=1$; Environment $=0$; Engineering $=-1$ \\
\cline { 2 - 3 } & Environment & Business $=0$; Education $=0$; Environment $=1$; Engineering $=-1$ \\
\hline
\end{tabular}

\section{Results}

The results of this study explore how engineering students' perspectives on sustainability compare to the vision of the engineering profession and to the perspectives of students in other types of majors.

\subsection{Sense of Personal Responsibility}

Engineering students cited multiple SDGs in their responses to the short answer question in the survey. How their responses compared to the 17 Agenda 2030 SDGs is summarized in Table 5.

Table 5. Engineering students' intentions to contribute.

\begin{tabular}{|c|c|c|c|c|c|}
\hline \multicolumn{2}{|r|}{ Sustainability Goal } & \multicolumn{2}{|c|}{$\begin{array}{l}\text { Number of Students Who } \\
\text { Cited SDG as Primary Goal }\end{array}$} & \multicolumn{2}{|c|}{$\begin{array}{c}\text { Students Who Cited SDG } \\
\text { as Secondary Goal }\end{array}$} \\
\hline$\#$ & Description & $n$ & $\%$ & $n$ & $\%$ \\
\hline 1 & No Poverty & 0 & $0 \%$ & 0 & $0 \%$ \\
\hline 2 & Zero Hunger & & & & \\
\hline 5 & Gender Equality & & & & \\
\hline 8 & Decent Work \& Economic Growth & & & & \\
\hline 10 & Reduced Inequalities & & & & \\
\hline 11 & Sustainable Cities \& Communities & & & & \\
\hline 14 & Life below Water & & & & \\
\hline 16 & Peace, Justice, \& Strong Institutions & & & & \\
\hline 17 & Partnerships for the Goals & & & & \\
\hline 3 & Good Health \& Well-Being & 1 & $0.4 \%$ & 0 & $0 \%$ \\
\hline 4 & Quality Education & 8 & $3.5 \%$ & 1 & $0.4 \%$ \\
\hline 6 & Clean Water \& Sanitation & 1 & $0.4 \%$ & 0 & $0 \%$ \\
\hline 7 & Affordable \& Clean Energy & 45 & $19 \%$ & 6 & $2.6 \%$ \\
\hline 9 & Industry, Innovation, \& Infrastructure & 2 & $0.9 \%$ & 1 & $0.4 \%$ \\
\hline 12 & Responsible Consumption \& Production & 75 & $32 \%$ & 6 & $2.6 \%$ \\
\hline 13 & Climate Action & 2 & $0.9 \%$ & 0 & $0 \%$ \\
\hline 15 & Life on Land & 2 & $0.9 \%$ & 1 & $0.4 \%$ \\
\hline-1 & Relevant response but no discernible SDG & 47 & $20 \%$ & 1 & $0.4 \%$ \\
\hline 0 & I don't know, irrelevant, or no response & 49 & $21 \%$ & 216 & $93 \%$ \\
\hline
\end{tabular}

Many students (20\%) responded in terms that were too generalized to code and many expressed thoughts (21\%) that did not align with modern conceptions of sustainability. Of those that provided specific responses in line with such modern conceptions, the largest number $(32 \%)$ envisioned their primary contribution to sustainability to be in line with SDG \#12 (responsible consumption and production) followed by 19\% who aligned with SDG \#7 (affordable and clean energy). Eight students $(3.5 \%)$ believed that contributing to educating others in sustainability (which is part of SDG \#4) was an important part of their contribution as professional engineers. Two students expressed an interest in contributing to each of SDGs \#9 (industry, innovation, and infrastructure), \#13 (climate action), and \#15 (life on land), and only a single student deemed \#3 (good health and wellbeing) or \#6 (clean water and sanitation) to be within their realm of influence as career engineers. Nine of the 17 SDGs were not noted by at least one student and 93\% of students mentioned only one (primary) SDG in their responses. 
Given the number of students who provided a response that could not be coded according to the 17 SDGs, our study turned to more close-ended, Likert-scale questions to understand differences between disciplines. These questions addressed personal responsibility for five of the specific challenges in sustainability that came up most frequently in our qualitative analysis in RQ1 (Table 5): Sustainable energy (under SDG \#7), climate change (under SDG \#13), education (under SDG \#4), resource scarcity (under SDG \#12), and waste management (under SDG \#12). Results of the quantitative analyses of these personal responsibility questions are described next.

\subsection{Differences among Disciplines}

Individual, Likert-scale questions asked students to express how strongly they agreed or disagreed with having personal responsibility for five critical issues in sustainability: Increasing sustainable energy, improving access to education, mitigating climate change, reducing proliferation of waste electronics, and addressing resource scarcity. For frequency analyses, responses from the five-point Likert scale were combined into three categories: Strongly disagree or disagree; strongly agree or agree; and neither/neutral. Results are summarized in Table 6.

Potential differences among types of majors were evaluated using chi-squared independence tests. Significant differences among the students in the four types of majors emerged in the level of personal responsibility students expressed for mitigating climate change, supporting sustainable energy, and reducing waste electronics. The strongest of these results (Cramer's V $=0.227$ ) occurred with personal responsibility regarding the mitigation of climate change. A strong majority of students in environmental sciences (92\%) strongly agreed or agreed that they held a future personal responsibility in this area while none of these students denied such responsibility. In contrast, education students were split between feeling responsible for mitigating climate change $(31 \%)$ or not $(28 \%)$, with many acknowledging strong feelings in neither direction (41\%). Nearly half of engineering students (46\%) expressed responsibility for climate change, despite the fact that most of the engineering students surveyed were mechanical or electrical engineers and had no coursework explicitly focused on climate change in their majors.

Significant differences among disciplines also emerged with regard to personal responsibility for contributing to the sustainability of energy. The strength of these differences was appreciable (Cramer's $\mathrm{V}=0.197)$ although not as strong as differences among students with regard to climate change. Similar to the climate change results, a strong majority of students in environmental science ( $82 \%$ ) felt responsible for sustainable energy but a majority of engineering students $(65 \%)$ did as well. In contrast, a minority of business (46\%) and education (36\%) students expressed such responsibility.

Similar results emerged with respect to personal responsibility for the proliferation of waste electronics although the effect size was small (Cramer's V $=0.101)$. A majority of both environmental $(55 \%)$ and engineering (58\%) students felt responsible for decreasing the proliferation of waste electronics in their careers while a minority of business $(42 \%)$ and education (36\%) students expressed such responsibility.

Among the remaining two issues examined (resource scarcity and access to education), no significant differences across majors emerged. With regard to access to education, between $40 \%$ and $50 \%$ of students in each of the four disciplines acknowledged professional responsibility for improving such access. A majority of environmental science (55\%) and engineering students (58\%) felt responsible for addressing resource scarcity, while a minority of business (42\%) and education $(38 \%)$ students acknowledged such responsibility. The differences in these results, however, were not statistically significant.

Overall, on these five critical issues of sustainability, more students in STEM fields expressed a strong sense of personal responsibility than students in non-STEM fields. Linkages between such personal responsibility and other personal and professional dimensions of responsibility for sustainable development were examined in the next set of analyses (associated with RQ3). 
Table 6. Sense of personal responsibility.

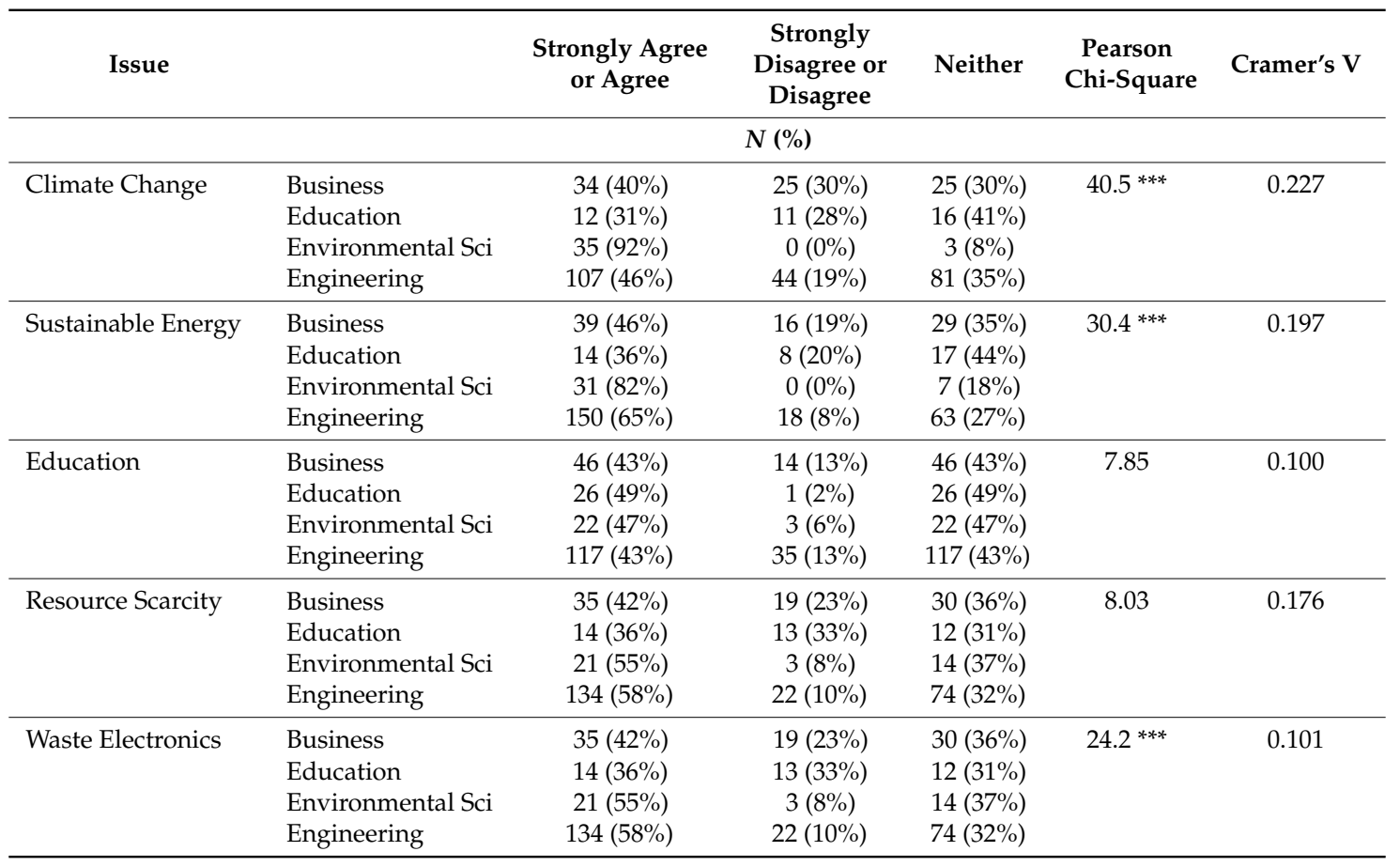

$$
* * * p<0.001 \text {. }
$$

\subsection{Professional Responsibility, Personal Knowledge, and Personal Responsibility}

In order to understand whether professional responsibility and personal knowledge are associated with personal responsibility, the five items measuring students' sense of personal responsibility in RQ2 were combined into a single scale. The resulting scale had good reliability (Cronbach's reliability of 0.87 ) and was used as the dependent variable in subsequent ANOVAs and regression models to understand potential linkages of interest. Scales measuring professional responsibility and personal knowledge as well as type of major were used as independent variables in these models.

Descriptive statistics for the three scales are summarized in Table 7. A one-way analysis of variance (ANOVA) showed significant differences in the means across disciplines for professional responsibility and personal responsibility but not for personal knowledge. Subsequent pairwise comparisons with Bonferroni correction to control for type 1 error showed that scores for students in environmental science were significantly higher than business, education, and engineering majors for professional responsibility and significantly higher for students in business for personal responsibility. No other pairwise comparisons emerged as significant.

Table 7. Responsibility and knowledge.

\begin{tabular}{|c|c|c|c|c|}
\hline & Business & Education & Environmental Science & Engineering \\
\hline & \multicolumn{4}{|c|}{ Mean (SD) } \\
\hline $\begin{array}{l}\text { Professional } \\
\text { responsibility *** }\end{array}$ & $3.87(0.65)$ & $3.79(0.65)$ & $4.39(0.53)$ & $3.93(0.63)$ \\
\hline Personal knowledge & $2.91(0.70)$ & $3.91(0.70)$ & $3.10(0.70)$ & $2.93(0.70)$ \\
\hline Personal responsibility ** & $3.33(0.77)$ & $3.42(0.79)$ & $3.79(0.60)$ & $3.55(0.75)$ \\
\hline
\end{tabular}

A hierarchical linear regression model was then constructed to evaluated how type of major, professional responsibility, and personal knowledge predicted personal responsibility. Type of major was effect coded into three different independent variables (business, education, environment) as described 
in Table 4 and inserted into the first level of the regression model (Model 1). The second level of the model included personal knowledge and professional responsibility scales as independent variables. The results of the model are summarized in Table 8.

In the first model (Model 1), students reporting a major associated with business significantly and negatively predicted personal responsibility while students in environmental studies majors were positively associated with personal responsibility. The strength of this model, however, was weak $\left(\mathrm{r}^{2}=0.028\right)$. When professional responsibility and personal knowledge were added the model (Model 2), type of major was no longer significant, suggesting that the contribution of type of major was based primarily on differences in personal knowledge or professional responsibility across types of major. Interactions between type of major and the other two independent variables were also investigated in a third level of the regression model. But, no interactions were found to be significant and these results are not reported.

Table 8. Hierarchical regression model (personal responsibility).

\begin{tabular}{ccccccc}
\hline Predictor Variable & \multicolumn{2}{c}{ Model 1 } & \multicolumn{3}{c}{ Model 2 } \\
\hline & \multicolumn{2}{c}{ Unstandardized Coefficient B (Standard Error) } \\
\hline & B (SE) & $\boldsymbol{p}$ & B (SE) & $\boldsymbol{p}$ & \\
\hline Constant & $3.52(0.05)$ & 0.000 & $* * *$ & $-0.13(0.19)$ & 0.506 & \\
Business & $-0.19(0.08)$ & 0.011 & $*$ & $-0.06(0.05)$ & 0.287 & \\
Education & $-0.10(0.10)$ & 0.303 & $0.05(0.07)$ & 0.492 & \\
Environment & $0.27(0.10)$ & 0.007 & $* *$ & $-0.06(0.07)$ & 0.417 & \\
\hline Professional responsibility & \multicolumn{7}{c}{$0.66(0.04)$} & 0.000 & $* * *$ \\
Personal knowledge & \multicolumn{7}{c}{0.028} & $0.34(0.04)$ & 0.000 & $* * *$ \\
\hline $\mathrm{r}^{2}$ & $* p<0.05 ; * * 0.01 ;{ }^{* * *} p<0.001$. & 0.512 & \\
\hline
\end{tabular}

\section{Discussion}

\subsection{Research Question \#1 (RQ1)}

Do engineering students expect to contribute to sustainability in ways that are consistent with national priorities for engineering? The overlap between Agenda 2030 Sustainability Goals (SDGs) [1] and the grand challenges of engineering [2] reflects the theme of sustainability that the National Academy of Engineering has emphasized and folded into these challenges (Figure 1). However, the alignment between the personal responsibility that engineering students in this study expressed for sustainability and those challenges is far less comprehensive (Figure 2).

In their responses, students did not address goals associated with good health and well-being (SDG \#3), clean water and sanitation (SDG \#6), industry, innovation, and infrastructure (SDG \#9), and peace, justice, and strong institutions (SDG \#16) despite the fact that one or more of the grand challenges of engineering did embody these goals. This result is consistent in many ways with previous studies that highlight the predominance of the environmental pillar of the TBL over social and economic pillars $[13,26]$. These results reinforce the need for engineering educators to improve sustainability education to include more topics that emphasize social and economic impacts of engineering practice. Furthermore, these results highlight a need to raise awareness and build skills to address the major challenges that face professional engineers in the 21st century. 


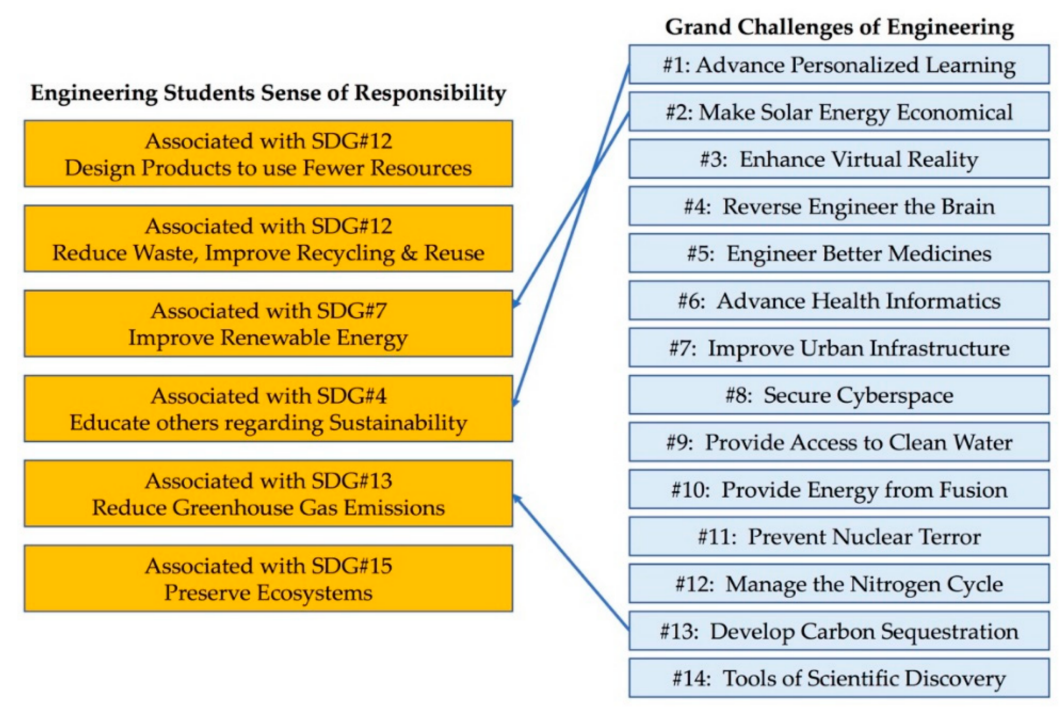

Figure 2. Engineering students' personal responsibility vs. national priorities of engineering.

\subsection{Research Question \#2 (RQ2)}

Do students in various (STEM and non-STEM) majors express a different sense of personal responsibility for specific challenges in sustainability? Not surprisingly, this study found that a greater percentage of STEM students (compared to non-STEM students) feel responsible for addressing sustainability challenges that directly relate to science (climate change) and technology (waste electronics, sustainable energy). This result, while expected, reinforces the idea that the intersection between STEM education and sustainability education is fairly unique and that educators should capitalize on the intrinsic motivations of these students to know and understand science and technology at a deeper level than non-STEM students. The disproportionately high numbers of environmental sciences students who felt responsible for positively impacting climate change and sustainable energy in their careers is likely to have been influenced by the large number of courses within their area of study that focused on sustainability (Table 2). Despite having much lower exposure to sustainability courses in their majors, a high percentage of engineering students $(65 \%)$ also expressed personal responsibility for sustainable energy compared to business (46\%) and education (36\%) majors.

In contrast, the percentages of engineering and (environmental) science students who feel responsible for addressing sustainability challenges (resource scarcity and access to education) that do not necessarily require technology to solve are not significantly different than non-STEM students. Whether or not science and technology are critical to addressing these two challenges, these results suggest that finding the challenges for which students feel greatest responsibility is key to creating a bridge between any STEM field and sustainability education. Without the motivation to know and understand that a sense of personal responsibility provides, sustainability is often incorporated superficially by students in their coursework or with substantial resistance from students $[14,15]$.

\subsection{Research Question \#3 (RQ3)}

How are students' professional responsibility and personal knowledge linked to their sense of personal responsibility for promoting sustainability? In this study, personal knowledge and professional responsibility both significantly predicted personal responsibility. According to the model for professional social responsibility for engineers developed by Canney and Bielefeldt (Figure 3), both personal and professional dimensions of ability and responsibility are necessary to stimulate socially responsible behavior. Once action is taken, a cycle begins whereby serving a particular social problem further increases the motivation and likelihood that an engineer will serve the social good in the future [27]. While this study is cross-sectional in nature, meaning that cause and effect cannot be accurately assessed, the results of this study do suggest that both professional and personal components of social responsibility influence each other. Personal 
knowledge predicts personal responsibility and professional responsibility also predicts personal responsibility. These connections suggest that positive feedback may occur between personal social awareness and professional development even before the professional connectedness cycle begins (Figure 3).

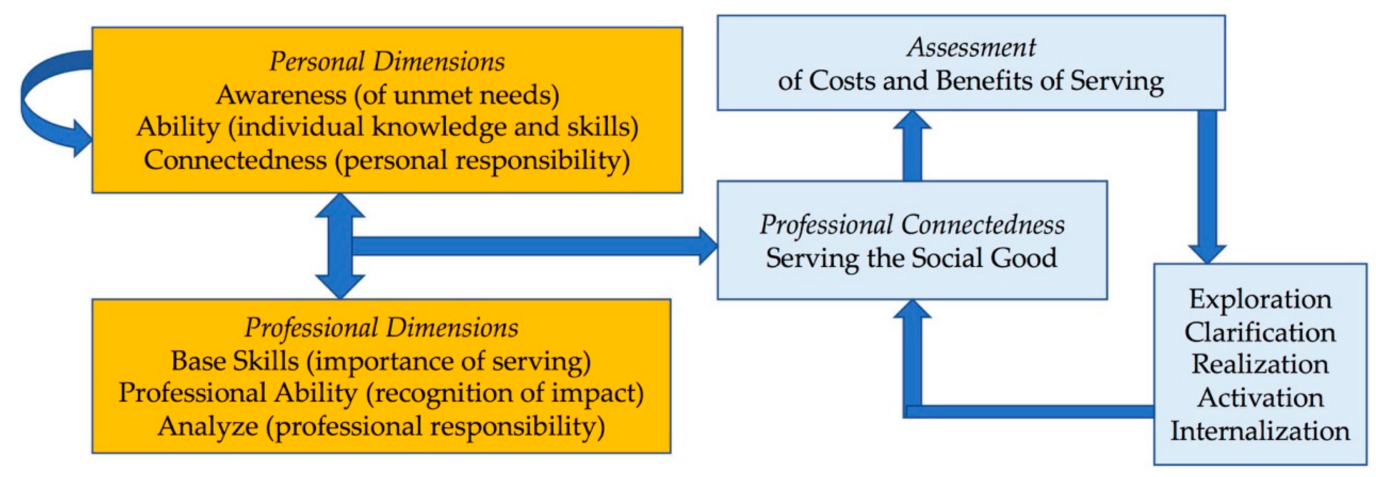

Figure 3. Professional social responsibility development model (adapted from [27]).

The results of this study suggest that personal dimensions of social responsibility may predict other personal dimensions and serve to enhance them in support of eventual action through professional connectedness. Professional dimensions may also serve to predict and enhance personal dimensions of social responsibility.

The results of this analysis also suggest that developing individual (personal) knowledge among students may have an independent effect on personal responsibility. While the result of the linear regression models show that professional responsibility is a stronger predictor of personal responsibility than personal knowledge $(\mathrm{B}=0.66)$, personal knowledge is still a significant predictor $(\mathrm{B}=0.34)$. In a curriculum and pedagogical climate dominated by content-driven lecture [9], this is good news. It implies that engineering educators can influence engineering students' propensity to act on sustainability by leveraging the development of personal knowledge in areas where engineering students already desire to contribute (Table 5).

\subsection{Limitations}

Although this research has provided insight into how engineering students view their contribution to the social good in engineering (through sustainability efforts) compared to how engineering experts and how other disciplines view that contribution, this study has limitations. The data is limited to a single institution and to a limited number of participants in environmental science, business, and education. In engineering, participants were limited primarily to mechanical and electrical engineering majors. Thus, the findings may not generalize to other engineering disciplines or to other institutions of higher education. While the study participants were chosen to represent a broad range of areas, there may be some self-selection bias among those who chose to complete the survey that has distorted the results. However, since many of the results of this research are consistent with previous studies that show that conceptions of sustainability among engineering students are limited, the likelihood that self-selection bias and single institution focus have compromised the accuracy and generalizability is reduced. Nevertheless, further research should be attentive to these issues to increase generalizability and reduce potential bias.

Another limitation of this study is that it is cross-sectional in nature and does not show cause and effect regarding the influence of personal dimensions of social responsibility (for sustainability) on other personal dimensions as well as on professional dimensions. The participant responses were gathered at one point in time, which means the relationships are based on concurrent responses. As such, the direction of effects between variables cannot be fully determined. While we do know that responsibility generally leads to action when an individual has appropriate skills or knowledge to act, longitudinal research is needed to fully explore and confirm the direction of these effects. 
Finally, the results of this study are potentially biased by student experiences. Course options in sustainability vary in emphasis and number of courses by major, which, in turn, can bias student perceptions. This is especially true at the upper level undergraduate level because many of the sustainability courses in Table 2 are offered at junior or senior level, meaning that upper level students have taken more of these courses or are simply more familiar with the option to take them. In the current study, it is also impossible to separate whether students' interest in sustainability led them to major in a field with multiple sustainability course offerings or whether such offerings increased interest in sustainability. However, comparing the content of sustainability courses in the environmental sciences program to the results of Table 6 reveals that higher percentages of environmental science students feel responsible for aspects of sustainability that are emphasized in their coursework but the same is not true in other areas that are not emphasized in their coursework (e.g., access to education). This result suggests that curriculum likely contributes to enhanced responsibility for specific sustainability issues. However, a longitudinal study would be necessary to fully explore this possibility.

\subsection{Implications}

The results of research question \#1 suggest that not only must the content of engineering curricula be adjusted to align with sustainability goals associated with Agenda 2030, it also must embody more of the grand challenges of engineering. The results associated with research question \#2 suggest that engineering can and should play a different role in sustainability education by capitalizing on what engineering students see as important in contrast to students in non-STEM fields. And, the results of research question \#3 suggest that even traditional content-heavy teaching techniques in engineering can build personal knowledge about sustainability challenges that, in turn, are strongly linked to engineering students' sense of personal responsibility and by extension, their propensity to act on that responsibility as they enter into the workforce.

\section{Conclusions}

This study has expanded on previous results that demonstrate evidence that engineering students are different in several ways from those in other disciplines, particularly non-STEM. Engineering students are highly invested in such challenges as sustainable energy and waste electronics, much more so than students in business and education. Teaching skills or content in these key areas of sustainability can be used as a gateway to maintain and expand student interest and commitment to other critical engineering and sustainability challenges. At a cross-sectional level, this study has also shown that student perceptions of personal knowledge and professional responsibility predict personal responsibility for sustainable development. Future work should include a larger, longitudinal study to understand how generalizable these results are and to identify directionality of the significant linkages (i.e., cause and effect) identified in this study.

Author Contributions: The author works on all parts of the research including framing of the study, collection and analysis of documents, and writing of the results.

Funding: This research was funded by National Science Foundation: DUE-1245464.

Acknowledgments: The authors would like to gratefully acknowledge the National Science Foundation for their support of this work under the TUES program (grant number DUE-1245464). Any opinions, findings, and conclusions or recommendations expressed in this material are those of the author(s) and do not necessarily reflect the views of the National Science Foundation.

Conflicts of Interest: The author declares no conflict of interest.

\section{References}

1. United Nations. Transforming our World: The 2030 Agenda for Sustainable Development: Sustainable Development Knowledge Platform. Available online: https://sustainabledevelopment.un.org/post2015/ transformingourworld (accessed on 27 April 2019). 
2. National Academy of Engineering. Grand Challenges-14 Grand Challenges for Engineering. Available online: http://www.engineeringchallenges.org/challenges.aspx (accessed on 2 February 2019).

3. Qureshi, A.S.; Nawab, A. The Role of Engineers in Sustainable Development. In Proceedings of the Symposium on Role of Engineers in Economic Development and Policy Formulation, Lahore, Pakistan, 2013; pp. 105-114.

4. United Nations. Agenda 21: Sustainable Development Knowledge Platform. Available online: https://sustainabledevelopment.un.org/outcomedocuments/agenda21 (accessed on 30 April 2019).

5. United Nations. SDG 4: Ensure Inclusive and Equitable Quality Education and Promote Lifelong Learning Opportunities for All. Available online: https://sdgcompass.org/sdgs/sdg-4/ (accessed on 30 April 2019).

6. Armstrong, C.M. Implementing education for sustainable development: The potential use of time-honored pedagogical practice from the progressive era of education. J. Sustain. Educ. 2011, 2, 1-19.

7. Cotton, D.; Bailey, I.; Warren, M.; Bissell, S. Revolutions and second-best solutions: Education for sustainable development in higher education. Stud. High. Educ. 2009, 34, 719-733. [CrossRef]

8. (ABET) Accreditation Board for Engineering and Technology. Criteria for Accrediting Engineering Programs, 2019-2020. Available online: https://www.abet.org/accreditation/accreditation-criteria/criteria-foraccrediting-engineering-programs-2019-2020/ (accessed on 30 April 2019).

9. Stains, M.; Harshman, J.; Barker, M.K.; Chasteen, S.V.; Cole, R.; DeChenne-Peters, S.E.; Eagan, M.K., Jr.; Esson, J.M.; Knight, J.K.; Laski, F.A.; et al. Anatomy of STEM teaching in North American universities. Science 2018, 359, 1468-1470. [CrossRef] [PubMed]

10. Orr, D.W. Earth in Mind: On Education, Environment, and the Human Prospect; Island Press: Washington, DC, USA, 2004.

11. Azapagic, A.; Perdan, S.; Shallcross, D. How much do engineering students know about sustainable development? The findings of an international survey and possible implications for the engineering curriculum. Eur. J. Eng. Educ. 2005, 30, 1-19. [CrossRef]

12. Bernstein, W.Z.; Ramanujan, D.; Cox, M.F.; Zhao, F.; Sutherland, J.W.; Ramani, K. Implementing design critique for teaching sustainable concept generation. In Proceedings of the 18th International Conference on Engineering Design (ICED 11), Impacting Society through Engineering Design; Design Education: Lyngby, Copenhagen, Denmark, 15-18 August 2011; Volume 8.

13. Burian, S. Teaching sustainability and sustainable engineering practice in the civil engineering curriculum. In Proceedings of the ASEE Annual Conference and Exposition, Louisville, KY, USA, 20-23 June 2010.

14. Seager, T.P.; Selinger, E. Experiential teaching strategies for ethical reasoning skills relevant to sustainability. In Proceedings of the Sustainable Systems and Technology, Tempe, AR, USA, 18-20 May 2009.

15. Braun, D. Teaching Sustainability Analysis in Electrical Engineering Lab Courses. IEEE Trans. Educ. 2010, 53, 243-247. [CrossRef]

16. Davidson, C.I.; Matthews, H.S.; Hendrickson, C.T.; Bridges, M.W.; Allenby, B.R.; Crittenden, J.C.; Chen, Y.; Williams, E.; Allen, D.T.; Murphy, C.F.; et al. Viewpoint: Adding Sustainability to the Engineer's Toolbox: A Challenge for Engineering Educators. Environ. Sci. Technol. 2007, 41, 4847-4849. [CrossRef] [PubMed]

17. (NSF) National Science Foundation. Science and Engineering Indicators 2018. Available online: https://www.nsf.gov/statistics/2018/nsb20181/report/sections/higher-education-in-science-and-engineering/ undergraduate-education-enrollment-and-degrees-in-the-united-states (accessed on 27 April 2019).

18. Morais, D.B.; Ogden, A.C. Initial development and validation of the global citizenship scale. J. Stud. Int. Educ. 2011, 15, 445-466. [CrossRef]

19. Roberts, R. Evaluating Psychographic Measures among Undergraduates: Relevance to Marketing of Sustainable Tourism. Master's Thesis, University of Washington, Seattle, WA, USA, 2015.

20. Roberts, R.; Wilson, D. Cross-Validation of a Global Citizenship Scale: Constructs for Evaluating Undergraduate Engineering Perspectives. In Proceedings of the ASEE Annual Conference and Exposition, New Orleans, LA, USA, 26 - 29 June 2016.

21. Braun, V.; Clarke, V. Using thematic analysis in psychology. Qual. Res. Psychol. 2006, 3, 77-101. [CrossRef]

22. Coffey, A.; Atkinson, P. Making Sense of Qualitative Data: Complementary Research Strategies; Sage Publications: Thousand Oaks, CA, USA, 1996.

23. Guest, G.; MacQueen, K.M.; Namey, E.E. Applied Thematic Analysis; Sage Publications: Thousand Oaks, CA, USA, 2011. 
24. Walther, J.; Sochacka, N.W.; Kellam, N.N. Quality in interpretive engineering education research: Reflections on an example study. J. Eng. Educ. 2013, 102, 626-659. [CrossRef]

25. McHugh, M.L. The chi-square test of independence. Biochem. Medica 2013, 23, 143-149. [CrossRef]

26. Kelly-Quattrochhi, S.; Wilson, D.M.; Roberts, R.; Yonemura, R. Is Protecting the Environment All There Is to Sustainability? In Proceedings of the ASEE Annual Conference and Exposition, New Orleans, LA, USA, 26-29 June 2016.

27. Canney, N.; Bielefeldt, A. A framework for the development of social responsibility in engineers. Int. J. Eng. Educ. 2015, 31, 414-424.

(C) 2019 by the author. Licensee MDPI, Basel, Switzerland. This article is an open access article distributed under the terms and conditions of the Creative Commons Attribution (CC BY) license (http://creativecommons.org/licenses/by/4.0/). 